\title{
Addressing the elephant in the room: a possible new way to increase patient adherence to medical advice
}

This article was published in the following Dove Press journal:

Patient Preference and Adherence

28 June 2017

Number of times this article has been viewed

\author{
Gudmund Grønhaug \\ Department of Public Health \\ and Nursing, Faculty of Medicine \\ and Health Sciences, Norwegian \\ University of Science and Technology, \\ Trondheim, Norway
}

\begin{abstract}
Lack of patient adherence to medical advice (PAMA) is recognized as an area of interest. None of the previous initiatives to improve PAMA, such as patient centered care and shared decision making, have proved to be successful in terms of improving patient adherence. The aim of the present study is to assess beliefs about priorities in public health care, and adherence to medical advice, to establish a novel approach to increase PAMA. The present study is based on responses to two questions in an experimental survey from the Norwegian Citizen Panel, addressing people's attitudes to priorities in public health care and adherence to medical advice. The questions on priorities in the health care sector are organized into six groups. The questions on adherence are organized into three groups. All questions are answered on a 7-point Likert scale. This study is the first to use experimental surveys to assess PAMA. The results indicate that if health care providers refer to national expertise and patient organizations' recommendations on a given treatment, PAMA could improve. Although technical and methodological interventions in health care have, to some extent, improved PAMA, medical adherence is still low. In the present study, it is shown that integrating either national expertise or collaborated messages with other health professions and patient organizations' recommendations in everyday care may help improve patients adherence to medical advice. A minor change in how treatment suggestions are presented could improve PAMA.
\end{abstract}

Keywords: adherence, medical advice, primary care, interprofessional collaboration, patient centered care, patient organization

\section{Introduction}

The outcome of health care interventions depends heavily on complex psychological and sociocultural factors of which many are out of health professionals' control. One important factor for successful health interventions is patient adherence to a presented treatment plan, as agreed upon during consultation. Lack of patient adherence has been recognized as an area of interest for the last few decades. ${ }^{1,2}$ Although counterintuitive, patient adherence to medication and/or a training regimes does not seem dependent on whether the medical issue is chronic, acute, critical, or a minor problem for the patient. ${ }^{3,4}$ In everyday practice, it is essential to take lack of adherence into consideration when setting up a treatment plan.

The recent focus on how to communicate with patients and taking patient concerns into consideration by listening to the patients' stories may help improve health care. ${ }^{5}$ Patient centered care and shared decision making are ways of integrating the patient as an expert on their own condition. The intention is that shared decision making and patient-centered care should empower patients by letting them tell their stories
Correspondence: Gudmund Grønhaug Department of Public Health and Nursing, Faculty of Medicine and Health Sciences, Norwegian University of Science and Technology, Postboks 8905 Trondheim, N-749I, Norway

Tel +479596 I450

Email gudmund.gronhaug@ntnu.no 
uninterrupted. Health care providers have for decades been aware of the fact that interrupting a patient's story telling could result in loss of valuable, clinically relevant information from the patient. ${ }^{6}$ By interrupting the patient during consultation, the health care provider could further contribute negatively to the patient's adherence to the medical advice given. Still patients are interrupted several times during a consultation. ${ }^{6}$ Although there is no reason to believe that patient-centered care and shared decision making is anything but beneficial, the effects of shared decision making cannot currently be evaluated properly. ${ }^{7}$

Interprofessional collaboration is considered a necessity for developing a patient-centered health care system and is further seen as an effective way to increase adherence to medication and training regimes for patients. ${ }^{8,9}$ Interprofessional collaboration is now so widespread that most health care institutions teach interprofessional collaboration as a mandatory class in their professional health care education programs. This changes the way health professionals are organized on all levels. Furthermore, it could positively change how health care providers communicate with their patients. In Norway, this reorganization of health care services has also been implemented on a national level. ${ }^{10}$ Interprofessionalism is intended to optimize the use of limited resources available in the health care sector. Although assumed beneficial both for the health care system and the patients, very few studies have investigated the effects of interprofessional education from the patient's point of view. ${ }^{11,12}$

Other strategies for improving patient adherence are the introduction of e-health and m-health programs. Although promising from a cost-benefit perspective, there is no evidence that these methods increase adherence any more than personal contact. ${ }^{13,14}$ When consulted, health professionals appear to understand and communicate well with the patient across cultural differences, adherence to medical advice tends to increase. ${ }^{15}$ However, in studies on interpersonal relationships, findings suggest that physicians tend to rate their own communicating skills higher than what the patient perceive. ${ }^{16}$ The integration of social and cultural aspects of medical adherence in everyday health care appears to be incomplete. ${ }^{17}$ One possible reason for this could be that literature and research seem to focus more on technical methodology rather than underlying factors that influence effectivity and generalizability across different settings. ${ }^{18}$

Implementing yet another guideline or new technology is difficult and time-consuming and not always successful in day-to-day practice. ${ }^{1,19}$ So far, it seems that neither introducing new techniques of consultation and communication with the patients nor introducing novel technologies such as m-health and e-health is improving patients' adherence. It is time to take a step back and rethink how adherence increasing measures are conceptualized. Could adherence be increased without adding complexity to health care consultations and communication?

The aim of the present study is to assess beliefs about priorities in public health care, and adherence to medical advices to establish a novel approach to increase patient adherence to medical advice (PAMA).

\section{Methods}

The Norwegian Citizen Panel (NCP) is an experimental webbased survey. NCP represents a sample of the Norwegian population above the age of 18 years based on a random selection performed by the Norwegian National Registry. Recruitment was conducted by postal mail in November 2013 and October 2014. At both rounds of recruitment, a national sample of about 25,000 individuals received an invitation to participate in the panel. The resulting panel consists of about 5,000 active participants. Each round of surveys constitutes a representative cross-section of the Norwegian population from the panels' 5,000 active respondents. Only invited individuals can become respondents in the surveys. Panel members complete an online questionnaire approximately twice a year, with a lottery ticket for a 25,000 NOK travel voucher as incentive, to increase the response rate. Each questionnaire consists of several questions on politics, health, and social life in general. Each survey takes about 20 minutes to complete.

Respondents are randomized to answer similar questions with slightly different wording. To assess the respondents' view on official priorities in the health care sector, respondents to question $1 \mathrm{a}-\mathrm{f}$ were divided into six groups (265-285 respondents in each group). Questions 1a and 1d assess the respondents' views on official priorities (control group). In questions $1 \mathrm{~b}$ and $1 \mathrm{e}$, official priorities are affecting a family member. In questions $1 \mathrm{c}$ and $1 \mathrm{f}$, the respondents themselves are affected by these priorities.

To assess acceptance of a medical advice the respondents to question 2 were divided into three groups (523-564 respondents in each group). In question $2 \mathrm{a}$, the medical doctor is rejecting a treatment (control group). In question $2 b$, the medical doctor is rejecting the treatment with support from national expertise. In question $2 c$, the rejection of treatment is supported by both national expertise and the patient organization.

All surveys are opened by informing of the purpose of the survey. Completion of the survey is regarded as informed consent. 
Further information on the wording of questions and multiple choice answers is presented in the Supplementary material. Further information on selection, methods and statistics is published elsewhere..$^{20}$

\section{Ethics}

The Regional Committees for Medical and Health Research, REC West, approved the ethics of the study (Rek Vest \# 2013/2217).

\section{Statistics}

Stata version 12.0 was used to calculate sample mean (SM) values and confidence intervals (CIs).

\section{Results}

Question 1 (Table 1) was answered by 1,637 respondents, randomized to answer one of six different questions. Main rationale for health care priorities was assessed in questions 1a (SM 0.7442 CI 0.7169-0.7714) and 1d (SM 0.5226 CI 0.4877-5.576) (control group). Questions 1b (SM 0.7596 CI (0.7329-0.7864) and 1e (SM 0.5560 CI 0.5208-0.5912) assess how the respondents' views on main priorities for health care are affected if the patient had been a family member. Questions 1c (SM 0.7600 CI 0.7341-0.7860) and 1f (SM 0.5818 CI 0.5465-0.6171) assess how the respondents' views could be affected if the health priorities had direct consequences for themselves. Question 2 (Table 2) was answered by 1,626 respondents, randomized to answer one of the three possible subquestions. Question 2 showed an increasing support of the doctor's rejection of a wanted treatment when the advice was presented as supported by others: a rejection presented as the medical doctor's own decision (SM 0.5009 CI $0.4774-0.5245$ ), the doctor presented the rejection as a result of his adherence to national experts' guidelines (SM 0.5361 CI 0.5117-0.5604), or the rejection was based on both national expertise and recommendations from a patient organization (SM 0.5730 CI 0.5478-0.5982).

\section{Discussion}

This is probably the first time an experimental survey has been used to assess values and beliefs on health care priorities. It is also probably the first survey to use this methodology to assess a possible new intervention to increase PAMA.

All six questions regarding health care priorities showed significant support to official priorities in the health care services (Table 1). Furthermore, the results show significant support for a possibly new approach to increase adherence to medical advice (Table 2).

Evidence suggests that strong public support for health care priorities can provide a solid base for building trust in individual health care consultations, possibly resulting in higher adherence to the medical advice provided. The results of this study indicate no significant difference in how the respondents view health care priorities if these priorities are affecting a family member or themselves. Lack of trust in health care priorities could make people reluctant to contact a health care provider when feeling sick, or they may prefer to seek advice from alternative therapists. This makes public support for the health care system and its priorities vital to public health.

Patients' lack of adherence to medical advice is a concern, ${ }^{1,2}$ and there have been taken several approaches to increase adherence, none of which has proven superior. Previous attempts to increase patient adherence, such as patient centered care and shared decision-making, has focused on "in office processes" with the health care provider as the main

Table I Assessment of responses to main rationale for health care priorities

\begin{tabular}{|c|c|c|c|c|c|}
\hline \multirow{2}{*}{$\begin{array}{l}\text { Question } \\
\text { number }\end{array}$} & \multirow[t]{2}{*}{ Question phrases } & \multirow{2}{*}{$\begin{array}{l}\text { Sample } \\
\text { mean* }\end{array}$} & \multicolumn{2}{|c|}{$95 \%$ confidence interval } & \multirow[t]{2}{*}{$\mathbf{N}=\mathbf{I}, 637$} \\
\hline & & & Lower bound & Upper bound & \\
\hline I & Prioritizing waiting lists for surgery & & & & \\
\hline la & Patients with severe illness are treated first & 0.7442 & 0.7169 & $0.77 \mid 4$ & 271 \\
\hline Ib & $\begin{array}{l}\text { Patients with severe illness are treated first resulting in } \\
\text { longer waiting for one in your family }\end{array}$ & 0.7596 & 0.7329 & 0.7864 & 285 \\
\hline Ic & $\begin{array}{l}\text { Patients with severe illness are treated first resulting in } \\
\text { longer waiting for yourself }\end{array}$ & 0.7600 & 0.7341 & 0.7860 & 266 \\
\hline Id & Those who benefit most from treatment are prioritized & 0.5226 & 0.4877 & 0.5576 & 265 \\
\hline le & $\begin{array}{l}\text { Those who benefit most from treatment are prioritized } \\
\text { resulting in longer waiting for one in your family }\end{array}$ & 0.5560 & 0.5208 & 0.5912 & 277 \\
\hline If & $\begin{array}{l}\text { Those who benefit most from treatment are prioritized } \\
\text { resulting in longer waiting for yourself }\end{array}$ & 0.5818 & 0.5465 & 0.6171 & 273 \\
\hline
\end{tabular}

Notes: Questions la-f are used to assess beliefs on health care system priorities. All questions are answered using a 7-point Likert scale. Results are based on positive attitude regarding wording in the question. *Sample mean positive to wording in phrase. 
Table 2 Assessment of patient adherence

\begin{tabular}{|c|c|c|c|c|c|}
\hline \multirow{2}{*}{$\begin{array}{l}\text { Question } \\
\text { number }\end{array}$} & \multirow[t]{2}{*}{ Question phrases } & \multirow{2}{*}{$\begin{array}{l}\text { Sample } \\
\text { mean* }\end{array}$} & \multicolumn{2}{|c|}{$95 \%$ confidence interval } & \multirow[t]{2}{*}{$\mathbf{N}=\mathbf{I , 6 2 6}$} \\
\hline & & & Lower bound & Upper bound & \\
\hline 2 & Treatment rejection & & & & \\
\hline $2 a$ & Medical doctor denies treatment & 0.5009 & 0.4774 & 0.5245 & 539 \\
\hline $2 b$ & Medical expertise does not approve the treatment** & 0.5361 & 0.5117 & 0.5604 & 564 \\
\hline $2 c$ & $\begin{array}{l}\text { Medical expertise and patient organization agree on } \\
\text { not approving the treatment** }\end{array}$ & 0.5730 & 0.5478 & 0.5982 & 523 \\
\hline
\end{tabular}

Notes: Questions 2a-c are used to assess aspects of potential new ways to increase patient adherence. All questions are answered using a 7-point Likert scale. Result is based on positive attitude regarding wording in the question. *Sample mean positive to wording in the phrase. **Question phrases refer to how the physician explains to the patient why the treatment is rejected.

target of improvement. Being a good listener, showing empathy and having good communication skills is of course an important part of being a good health care provider. However, it seems insufficient when it comes to improving PAMA. ${ }^{12}$

The results of this study indicate that respondents are more likely to adhere to medical advice if the health care provider informs them that this advice is also recommended by national expertise and patient organizations.

The time spent consulting is limited and should be used wisely. Most health care providers spend considerable time during consultations explaining interventions and treatment options, especially when the patient has received contradictory advice from different health care providers. If all health care providers and patient organizations communicate the same message to the patients for given diagnoses, this would save a lot of time and make consultations more effective.

This new way of communicating with patients will probably not be applicable for all diagnoses as not all diagnoses are covered by patient organizations. The findings of this study still show the importance of health care providers communicating to their patients with a uniform message for the main principles of treatment, also if there is no patient organization at hand.

The results of the present study provide new insight on what is lacking in previous attempts to improve PAMA.

According to developmental psychologists, there is a higher chance for a given change in behavior if individuals close to the person, who are in a process of changing, support the possible change. Bronfenbrenner, one of the most influential researchers in developmental psychology, organized society in four different societal hierarchical categories influencing the individual. ${ }^{21}$ If a person in the same societal hierarchical level, a family member, or a close friend suggests a behavioral change, it is more likely to be accepted and internalized than if the same advice comes from a person at the same level in the hierarchy. Furthermore, the change is more likely to be accepted if the same message is received from different levels in the societal hierarchy. Bronfenbrenner's theory is refined by Lewis, who states that power is a ubiquitous part of meaning-making. Lewis further addresses power in social assemblages in everyday life as a part of the meaning-making and points out that certain social structures attempt to fixate power to ensure their hegemony. ${ }^{22}$

Patient-centered care and shared decision making are the health care system's tools for empowering the patient during consultation. These tools are implemented as means to increase adherence to medical advice by making the patient the expert of their illness perceptions. By making the patient the expert and the owner of the symptoms, these consulting tools are meant to even-out some of the hierarchical differences between the patient and the health care provider. Both patient-centered care and shared decision making are proven to be more beneficial than usual consulting, but they are still in need of improvement to further address patient needs. ${ }^{1}$

The findings in the present study indicate that the respondents are more adherent to medical advice if the same advice given from the health care providers is also advocated by a patient organization. The reason for this may be that by referring to both national expertise and patient organizations, the message from the health care provider is given power both from higher and lower societal hierarchical levels. This opens for a new approach to increase PAMA. Although a small feature in a complex meaningmaking process, these findings suggest that informing the patient about patient organizations' recommendations together with national expertise's recommendations for the best treatment of a given condition may increase patient adherence, even when the suggested treatment differs from what the patient expected. This novel approach is applicable to patient-centered care and shared decision making and traditional health service examination protocols and will not take more than a few seconds from the consultation time. 


\section{Limitations}

The current study has both strengths and weaknesses. The study design may be taken as a weakness of the study. In an online survey, it is not given that respondents would respond the same way if the treatment rejection was given in a real-life setting. Furthermore, the respondents may be considered "professional" since they answer online surveys approximately twice a year. Whether this would make the data more positively or negatively skewed is unclear.

The study design is clearly also a strong point of this study. The experimental survey design gives researchers an opportunity to explore how similar groups reply to different questions on the same subjects. This may be seen as the survey equivalent to a randomized control trial. Moreover, it is a strength that the respondents were asked to respond to a rejection of a treatment. Having a patient accept a rejection of a requested treatment has proven more difficult than motivating them to accept a treatment.

Although the overall result of the survey indicates a significant difference in the potential adherence to medical advice, it is still not a robust finding. However, these signs of change in adherence are a clear indication of a possible powerful change over time. The potential change in adherence is based on a non-invasive and minor change in approach that is free of cost and without the risk of side effects.

\section{Conclusion}

Although technical and methodological interventions in health care have, to some extent, improved PAMA, medical adherence is still low. In the present study, it is shown that integrating either national expertise or collaborated messages with other health professions' and patient organizations' recommendations in everyday care may help improve PAMA.

\section{Acknowledgments}

All materials for the analyses and the statistics were provided by the NCP for use in this paper. Sveinung Arnesen and Elisabeth Ivarsflaten have been kind supporters of the work on this paper.

\section{Disclosure}

The author reports no conflicts of interest in this work.

\section{References}

1. Costa E, Giardini A, Savin M, et al. Interventional tools to improve medication adherence: review of literature. Patient Prefer Adherence. 2015;9:1303-1314
2. Dunbar J. Adherence to medical advice: a review. Int J Medical Health 1980;9:70-87.

3. Oberlin SR, Parente ST, Pruett TL. Improving medication adherence among kidney transplant recipients: Findings from other industries, patient engagement, and behavioral economics-A scoping review. SAGE Open Med. 2016;4:2050312115625026.

4. Conn V, Ruppar T, Chase J, Enriquez M, Cooper P. Interventions to improve medication adherence in hypertensive patients: systematic review and meta analysis. Curr Hypertens Rep. 2015;12(17):94.

5. Donaldson LJ. The wisdom of patients and families: ignore it at our peril. BMJ Quality \& Safety. 2015;24(10):603-604.

6. Beckmann HB, Frankel RM. The effect of physician behaviour on the collection of data. Ann Intern Med. 1984;101(5):692-696.

7. Phillips NM, Street M, Haesler E. A systematic review of reliable and valid tools for the measurement of patient participation in healthcare. BMJ Quality \& Safety. 2016;25(2):110-117.

8. Bridges DR, Davidson RA, Odegard PS, Maki IV, Tomkowiak J. Interprofessional collaboration: three best practice models of interprofessional education. Med Educ Online. 2011;16:0.3402/meo. v16i0.6035.

9. Langhorne P. Collaborative systematic review of the randomised trials of organised inpatient (stroke unit) care after stroke. BMJ. 1997;314(7088):1151.

10. omsorgsdepartement dkh-o. Nasjonal plan for habilitering og rehabilitering 2008-2011. Stortingsmelding 47 2008-2009; 2009. [Care department dkh-o. National Plan for Habilitation and Rehabilitation 2008-2011. Major Report 47 2008-2009; 2009]. Available from: https:// www.regjeringen.no/globalassets/upload/hod/sha/sartrykk-av-st.prp. nr.1-kapittel-9.pdf. Accessed April 12, 2017. Norwegian.

11. Zwarenstein M, Goldman J, Reeves S. Interprofessional collaboration: effects of practice based intervensions on professional practice and health care outcomes. Cochrane Database Syst Rev. 2009;(3): Art. No. CD000072.

12. Shay LA, Lafata JE. Where is the evidence? A systematic review of shared decision making and patient outcomes. Med Decis Making. 2015; 35(1):114-131.

13. Free C, Phillips G, Galli L, et al. The effectiveness of mobile-health technology-based health behaviour change or disease management interventions for health care consumers: a systematic review. PLoS medicine. 2013;10(1):e1001362.

14. Bassi N, Karagodin I, Wang S, et al. Lifestyle modification for metabolic syndrome: a systematic review. Am J Med. 2014;127(12):1242. e1241-e1210.

15. Ohana S, Mash R. Physician and patient perceptions of cultural competency and medical compliance. Health Educ Res. 2015;30(6): 923-934.

16. Stojan JN, Clay MA, Lypson ML. Assessing patient-centred care through direct observation of clinical encounters. BMJ Quality \& Safety. 2016;25(3):135-137.

17. Kiran T, Pinto AD. Swimming 'upstream' to tackle the social determinants of health. BMJ Quality \& Safety. 2016;25(3):138-140.

18. Pitt M, Monks T, Crowe S, Vasilakis C. Systems modelling and simulation in health service design, delivery and decision making. BMJ Quality \& Safety. 2016;25:38-45.

19. Grol R, Grimshaw J. From best evidence to best practice: effective implementation of change in patients' care. The Lancet. 2003; 362(9391): 1225-1230.

20. Ivarsflaten E. Norwegian Citizen Panel Wave 2, 2014. University of Bergen 2016.

21. Bronfenbrenner U. The ecology of human development: experiments by nature and design. Harvard: Harvard University Press; Cambridge, MA. 1979.

22. Lewis J. From culturalism to transculturalism. Iowa Journal of Cultural Studies. 2002;1:14-32. 


\section{Supplementary materials Questions used in the present study}

\section{Variable Ia}

Reasonable: waiting list for knee surgery, serious illness as a main rule should advance in line.

Literal question: imagine that there is a waiting list for knee surgery and that surgery would improve the knee function equally for everyone. To which extent do you agree or disagree that those with the most serious illness as a main rule should advance in line, even though that means that others would have to wait longer?

\section{Variable Ib}

Reasonable: someone close to you is on the waiting list for knee surgery, serious illness as a main rule should advance in line.

Literal question: imagine that someone close to you is on a waiting list for knee surgery and that surgery would improve the knee function equally for everyone on the waiting list. To which extent do you agree or disagree that those with the most serious illness as a main rule should advance in line, even though that means that a person close to you would have to wait longer?

\section{Variable Ic}

Reasonable: you are personally on the waiting list for knee surgery, serious illness as a main rule should advance in line.

Literal question: imagine that you are on a waiting list for knee surgery and that surgery would improve the knee function equally for everyone on the waiting list. To which extent do you agree or disagree that those with the most serious illness as a main rule should advance in line, even though that means that you would have to wait longer?

\section{Variable Id}

Reasonable: waiting list for knee surgery in patients with equally severe disease, those who will benefit most from treatment should advance in line.

Literal question: imagine that there is a waiting list for knee surgery among patients with equally serious illness. To which extent do you agree or disagree that those who would benefit most from the treatment as a main rule should advance in line, even though that means that others would have to wait longer?

\section{Variable le}

Reasonable: someone close to you is on the waiting list for knee surgery among patients with equally serious illness, those who will benefit most from treatment should advance in line.

Literal question: imagine that someone close to you is on a waiting list for knee surgery among patients with equally serious illness. To which extent do you agree or disagree that who would benefit most from the treatment as a main rule should advance in line, even though that means that the person close to you would have to wait longer?

\section{Variable If}

Reasonable: you personally are on the waiting list for knee surgery, serious illness as a main rule should advance in line even if you have to wait longer.

Literal question: imagine that you are on a waiting list for knee surgery among patients with equally serious illness. To which extent do you agree or disagree that those who would benefit most from the treatment as a main rule should advance in line, even though that means you would have to wait longer?

\section{Variable 2a}

Reasonable: patient with liveable disease hears about a treatment abroad, but the doctor decides that it cannot be offered.

Literal question: do you think that the hospital acts reasonably or unreasonably in this example. Imagine a patient undergoing hospital treatment for an illness that one can live with, but where there is a risk of significant deterioration over time. The patient has heard of new treatment abroad, and wonders why the hospital does not offer this treatment. The reason is that the patient's physician has thoroughly assessed the treatment and decided that it will not be offered. The patient is informed of this and is not offered treatment.

I think the hospital acted...

\section{Variable $2 b$}

Reasonable: patient with livable disease hear about a treatment abroad, but professional expertise determines that it cannot be offered.

Literal question: do you think that the hospital acts reasonably or unreasonably in this example. Imagine a patient undergoing hospital treatment for an illness that one can live with, but where there is a risk of significant deterioration over time. The patient has heard of new treatment abroad and wonders why the hospital does not offer this treatment. The reason is that the country's foremost professional expertise has thoroughly assessed the treatment and agreed that it will not be offered. The patient is informed of this and is not offered treatment.

I think the hospital acted... 


\section{Variable $2 c$}

Reasonable: patient with livable disease hear about a treatment abroad, but professional expertise and patient organizations determine that it will not be offered.

Literal question: do you think that the hospital acts reasonably or unreasonably in this example. Imagine a patient undergoing hospital treatment for an illness that one can live with, but where there is a risk of significant deterioration over time. The patient has heard of new treatment abroad and wonders why the hospital does not offer this treatment.
The reason is that the country's foremost professional expertise in consultation with patient organization representatives have thoroughly assessed the treatment and agreed that it will not be offered. The patient is informed of this and is not offered treatment.

I think the hospital acted...

All questions gave the answering opportunities of: very acceptable, acceptable, somewhat acceptable, neither acceptable nor unacceptable, somewhat unacceptable, unacceptable, and very unacceptable.

\section{Publish your work in this journal}

Patient Preference and Adherence is an international, peer-reviewed, open access journal that focuses on the growing importance of patient preference and adherence throughout the therapeutic continuum. Patient satisfaction, acceptability, quality of life, compliance, persistence and their role in developing new therapeutic modalities and compounds to optimize clinical outcomes for existing disease states are major areas of interest for the journal. This journal has been accepted for indexing on PubMed Central. The manuscript management system is completely online and includes a very quick and fair peer-review system, which is all easy to use. Visit http://www. dovepress.com/testimonials.php to read real quotes from published authors. 